\title{
UTILIZAÇÃO DE UMA TÉCNICA RÁPIDA EM CAMADA DELGADA PARA AVALIAÇÃO DA ATIVIDADE MICOBACTERICIDA DE DESINFETANTES QUÍMICOS
}

\author{
F. Morato*, R.A. Dias, A.P. Gonçales, GO. de Souza, J.J. Pereira, S.R. Pinheiro
}

Universidade de São Paulo, Faculdade de Medicina Veterinária e Zootecnia, Departamento de Medicina Veterinária Preventiva e Saúde Animal, Av. Prof. Dr. Orlando Marques de Paiva, 87, CEP 05508, São Paulo, SP, Brasil. E mail: flamorato@usp.br

\section{RESUMO}

\begin{abstract}
A atividade micobactericida do hipoclorito de sódio (2,5\% de cloro ativo) foi avaliada frente a uma estirpe deMycobacterium bovis utilizando-se a técnica de cultivo em camada delgada de ágar Middlebrook 7H11 modificado, a qual foi comparada ao teste padrão realizado em tubos contendo meio de Stonebrink. Os testes foram realizados na presença e ausência de matéria orgânica e em duas temperaturas $\left(21 \pm 2^{\circ} \mathrm{C}\right.$ è̀ $\left.4^{\circ} \mathrm{C}\right)$. Os resultados obtidos nas contagens das unidades formadoras de colônias (U.F.C) nas placas e tubos foram transformados em percentual de redução (Tabela 1) os quais foram comparados entre as duas técnicas, mostrando que o hipoclorito de sódio apresentou percentuais iguais entre as placas e os tubos em todas as condições testadas (teste de Mann-Wihtney $p>0,05 ; \alpha=5 \%$ ). O desinfetante atingiu atividade micobactericida de $100 \% \mathrm{em}$ todas as condições, exceto quando à temperatura de $4^{\circ} \mathrm{C}$ e presença de matéria orgânica (teste de Kruskal-Wallis e teste de Dunn; $\mathrm{p}<0,05$ ). O percentual de redução foi maior quando na ausência de matéria orgânica e à temperatura ambiente (teste de Mann-Wihtney; $p<0,05)$. A técnica de cultivo em camada delgada mostrou-se viável para realização de testes de desinfetantes e permitiu uma visualização precoce das micobactérias (média de 7 dias). O hipoclorito de sódio 2,5\% teve a atividade micobactericida diminuída quando na presença de matéria orgânica e à temperatura de $4^{\circ} \mathrm{C}$.
\end{abstract}

PALAVRAS-CHAVE: Desinfetantes, Mycobacterium bovis, tuberculose, Middlebrook, camada delgada.

\begin{abstract}
USE OF A FAST THIN-LAYER TECHNIQUE FOR THE EVALUATION OF THE MYCOBACTERICIDAL ACTIVITY OF CHEMICAL DISINFECTANTS. The mycobactericidal activity of sodium hypochlorite (2.5\% of active chlorine) was evaluated against a strain of Mycobacterium bovis using the modified thin-layer Middlebrook 7H11 cultivation technique and it was compared to the test made in tubes with Stonebrink medium. The assays were performed either in the presence or absence of organic matter, at temperatures of $4^{\circ} \mathrm{C}$ and $21 \pm 2^{\circ} \mathrm{C}$. The colonycounting results were transformed into reduction percentages (Tabela 1) which were compared between the two techniques, showing the disinfectant had similar reduction percentages between plates and tubes in all conditions tested (Mann-Whitney test $\mathrm{p}<0.05 ; \alpha=5 \%$ ). The $2.5 \%$ sodium hypochlorite had a mycobactericidal activity of $100 \%$ in all conditions, except when in the presence of organic matter and at $4^{\circ} \mathrm{C}$ (Kurskall-Wallis test and Dunn test, $\left.\mathrm{p}>0.05\right)$. The reduction percentage was higher when in the absence of organic matter and at $21 \pm 2^{\circ} \mathrm{C}$ (Mann-Whitney test $p>0.05$ ). The modified thin layer cultivation technique was practicable for the realization of the disinfectant tests and allowed an earlier visualization of the colonies (7 days medium). The $2.5 \%$ sodium hypochlorite had its mycobactericidal activity diminished when in the presence of organic matter and at the temperature of $4^{\circ} \mathrm{C}$.
\end{abstract}

KEY WORDS: Disinfectants, Mycobacterium bovis, tuberculosis, Middlebrook, thin layer.

\footnotetext{
*Auxilio FAPESP.
} 


\section{INTRODUÇÃO}

A tuberculose é uma doença transmissível de importância em saúde pública e saúde animal, pois determina um quadro grave de doença no homem, e acarreta acentuadas perdas econômicas, devido à diminuição da produtividade dos rebanhos afetados. Sob condições favoráveis, o Mycobacterium bovis pode causar, em seres humanos, as mesmas formas clínicas e lesões patológicas que o $M$. tuberculosis, e a infecção de seres humanos pelo $M$. bovis ocorre, principalmente pela via aerógena, ou pela ingestão de alimentos contaminados (AcHA; SZYFRES, 1986).

Muito antes da descoberta de medicamentos para o tratamento dos doentes, a tuberculose em humanos já estava diminuindo nos países desenvolvidos, pois os programas sanitários adotados abrangiam linhas de ação em relação às fontes de infecção, às vias de transmissão, aos animais suscetíveis e ao controle de produtos de origem animal. (KLEEBERG, 1984). Dentre as principais ações aplicadas nos programas sanitários destinados ao controle da tuberculose bovina, destacam-se os procedimentos de desinfecção como instrumento efetivo no combate ao agente da doença no meio ambiente (Poliakov, 1975; Vera et al., 1985).

A necessidade de uma freqüente avaliação dos desinfetantes está embasada no princípio de que a análise química dos produtos não fornece todas as informações necessárias para a mensuração de sua atividade antimicrobiana, isto é possível com a execução de ensaios que avaliem adequadamente a influência de outros fatores tais como: o tipo e a origem da estirpe que está sendo testada, o preparo do inóculo, o princípio ativo do produto químico e a sua respectiva concentração, bem como a seleção dos produtos neutralizantes (PINHEIRO etal., 1992; CASTILloGuerrero et al., 1993; PINHEIRO et al., 1997).

As micobactérias apresentam elevada capacidade de sobrevivência às mais variadas condições ambientais, e por este motivo, têm sido alvo de estudo por parte de outros pesquisadores há décadas. WANG et al. (2005) afirmaram que as micobactérias são mais resistentes a desinfetantes que às demais bactérias em estado vegetativo devido à parede celular rica em lipídios.

No comércio estão disponíveis diversos tipos de desinfetantes químicos, no entanto, o critério para a escolha de um determinado princípio ativo é o potencial que o mesmo apresenta para o combate ao agente que se deseja eliminar. RUBIN (1983) destacou a atividade micobactericida do formaldeído, iodo, iodóforos e dos compostos clorados.

Considerando o fator crescimento lento de micobactérias patogênicas nos meios de cultura tradicionais, atualmente, uma avaliação da atividade micobactericida de desinfetantes químicos que aten- da às recomendações já mencionadas anteriormente, levaria cerca de quatro meses para ser realizado. $\mathrm{O}$ aperfeiçoamento do método microbiológico convencional para um rápido diagnóstico representa uma grande vantagem na luta contra a tuberculose no homem e no bovino (SCHABERG et al., 1995; MejIA et al., 1999).

A técnica da camada delgada foi desenvolvida para a pesquisa e detecção rápida de micobactérias no meio de Middlebrook 7H11 com visualização microscópica (IDIGORAs et al.,1995), e oferece como principais vantagens resultados mais precoces e a possibilidade do estabelecimento de uma identificação preliminar da micobactéria isolada, baseando-se nas características morfológicas das colônias. Portanto, pode ser utilizada como um método complementar para o diagnóstico da tuberculose humana e animal (MEJIA et al., 1999; MARCondes, 2002; DiB et al., 2006). Além disso, essa técnica dispensa microscópios especiais ou qualquer outro a parato técnico sofisticado, e pode ser usada em qualquer laboratório. Os técnicos que a executam devem ser treinados, porém, o aprendizado é rápido (IDIGORAs et al., 1995).

Marcondes (2002) e Diв et al. (2006) utilizaram a técnica da camada delgada para o cultivo do $M$. bovis obtendo bons resultados com tempo de crescimento entre 5 e 13 dias. Até o momento, não há registros na literatura pesquisada sobre um "teste rápido" de desinfetantes utilizando-se estirpes patogênicas de $M$. bovis recém isoladas de material de campo. Desta forma, justifica-se o presente trabalho, que valida uma técnica de cultivo em camada delgada de ágar Middlebrook 7H11 para o teste da atividade micobactericida de um desinfetante químico, reduzindo assim o tempo de realização do teste e acelerando a indicação de um produto desinfetante eficaz.

\section{MATERIAIS E MÉTODOS}

Os testes foram feitos em cabine de fluxo laminar, utilizando-se 8 placas de Petri de vidro estéreis $(9,5 \mathrm{~cm}$ de diâmetro) contendo quatro círculos de papel filtro de 2,5 cm de diâmetro. Todas as placas receberam 4 mL de suspensão bacteriana de 0,06 g de colônias diluídas em $100 \mathrm{~mL}$ de solução salina 0,85 \% estéril com 0,05\% de Tween 80 (Pinheiro, 1990; PNheiro, 1992). Duas placas do grupo A e duas do grupo B (constituídos de 4 placas cada) receberam como matéria orgânica $1 \mathrm{~mL}$ de soro de coelho estéril, e duas placas receberam o placebo $(1 \mathrm{~mL}$ de solução salina $0,85 \%$ estéril). Posteriormente, adicionou-se $4 \mathrm{~mL}$ do hipoclorito de sódio 2,5\% (grupo B) diluído a 1:8, e a solução salina $0,85 \%$ estéril no grupo controle (grupo A). Duas placas por grupo foram mantidas à tempe- 
ratura de $21 \pm 2^{\circ} \mathrm{C}$ e duas à de $4^{\circ} \mathrm{C}$ por 60 minutos, tempo padronizado para avaliar-se a ação do desinfetante. Em seguida, foram retirados 3 círculos de papel filtro por placa, os quais foram macerados em cadinho com $10 \mathrm{~mL}$ de solução neutralizante (meio de cultura TSB acrescido de 5\% de soro de coelho estéril). Da suspensão anterior retirou-se $1 \mathrm{~mL}$ para diluirem $9 \mathrm{~mL}$ de solução salina 0,85 \% resultando em uma suspensão a 1:100. Após centrifugação a $1000 \mathrm{G}$, durante 15 minutos, o sedimento foi ressuspenso em $2 \mathrm{~mL}$ de solução salina $0,85 \%$ estéril, semeados em duplicatas, as placas contendo $7 \mathrm{~mL}$ demeio deMiddlebrook 7H11 modificado (UNIVERSIDAD DELAS NACIONES UNIDAS,1998), e tubos contendo $7 \mathrm{~mL}$ de meio de Stonebrink (Centro Panamericano de Zoonosis, 1979).

As placas foram incubadas a $37^{\circ} \mathrm{C}$, em jarra de microaerofilia (5-10\% $\mathrm{CO}_{2}$ ), e lidas no sétimo dia pós - semeadura com auxílio de microscópio óptico comum no aumento de 100x. Os tubos com meio de Stonebrink foram incubados horizontalmente $37^{\circ} \mathrm{C}$ por 24 horas, até a obtenção da secagem da porção líquida quando foram fechados com rolha de cortiça e mantidos a $37^{\circ} \mathrm{C}$ por 28 dias, quando foi realizada a leitura utilizando-se critério de escores segundo o preconizado por PINHEIRO (2001) superfície demarcada (colônias quase confluentes), 5: 81 a 100\% da superfície demarcada (toda a superfície do meio tomada por colônias).

Foram calculadas as médias das contagens, das duas duplicatas, das U.F.C. nas placas e dos escores nos tubos. O valor médio obtido foi transformado em percentual de redução (Tabela 1) (PINHeIro, 2001), o qual foi analisado estatisticamente com o auxílio dos softwares SPSS for Windows- Realese 9.01 (1999) e INSTAT3.01 (1998). As Figuras1e2, do tipo "boxplot", representam a ação do desinfetante nas diferentes condições testadas. $\mathrm{O}$ desinfetante foi avaliado nas diferentes situações de temperatura e matéria orgânica (teste de Kruskal-Wallis e o teste de Dunn como confirmatório), e comparou-se o desempenho do produto entre placas e tubos (teste de Mann-Wihtney; nível de confiança $\alpha=5 \%$ ).

\section{RESULTADOS E DISCUSSÃO}

As leituras de U.F.C. obtidas na avaliação da atividade micobactericida do desinfetante em placas, com meio de Middlebrook 7H11, puderam ser efetuadasem aproximadamente sete dias. Entretanto, o tempo de leitura dos tubos com meio de Stonebrink só foi possível ser realizado com 28 dias. A variável tempo de leitura e execução das duas técnicas foi avaliada por MARCONDES et al. (2006) que comparou o tempo decrescimento nas placas enos tubos, demonstrando que o método de cultivo em placas possibilita a realização de leitura em menor tempo. Durmaz et al. (1985), Welchet al. (1993), IDIGORAs et al. (1995) e MEJIA et al. (1999) também demonstraram as vantagens do diagnóstico da técnica de camada delgada frente aos métodos tradicionais de cultivo de micobactérias relatando significativa redução no tempo para a observação das primeiras colônias com elevada sensibilidade em favor da técnica de camada delgada.

Tabela 1 - Percentual de redução de crescimento de $M$. bovis frente ao hipoclorito de sódio 2,5\% em placas de meio de Middlebrok 7H11 e tubos de meio de Stonebrink, considerando a temperatura de contato e a presença ou ausência de matéria orgânica - São Paulo - 2007.

\begin{tabular}{|c|c|c|c|c|c|c|c|c|}
\hline \multirow[t]{3}{*}{$\mathrm{R}$} & \multicolumn{4}{|c|}{ Placas } & \multicolumn{4}{|c|}{ Tubos } \\
\hline & \multicolumn{2}{|c|}{$4^{\circ} \mathrm{C}$} & \multicolumn{2}{|c|}{ TA } & \multicolumn{2}{|c|}{$4^{\circ} \mathrm{C}$} & \multicolumn{2}{|c|}{ TA } \\
\hline & smo & $\mathrm{cmo}$ & smo & $\mathrm{cmo}$ & smo & $\mathrm{cmo}$ & smo & $\mathrm{cmo}$ \\
\hline $1^{\mathrm{a}}$ & 100,0 & 100,0 & 100,0 & 100,0 & 100,0 & 100,0 & 100,0 & 100,0 \\
\hline $2^{\mathrm{a}}$ & 100,0 & 100,0 & 100,0 & 100,0 & 100,0 & 100,0 & 100,0 & 100,0 \\
\hline $3^{\mathrm{a}}$ & 100,0 & 100,0 & 100,0 & 100,0 & 100,0 & 100,0 & 100,0 & 100,0 \\
\hline $4^{\mathrm{a}}$ & 100,0 & 98,6 & 100,0 & 100,0 & 100,0 & 71,4 & 100,0 & 100,0 \\
\hline $5^{a}$ & 100,0 & 100,0 & 100,0 & 100,0 & 100,0 & 100,0 & 100,0 & 100,0 \\
\hline $6^{\mathrm{a}}$ & 100,0 & 97,7 & 100,0 & 100,0 & 100,0 & 60,0 & 100,0 & 100,0 \\
\hline $7^{\mathrm{a}}$ & 100,0 & 100,0 & 100,0 & 100,0 & 100,0 & 100,0 & 100,0 & 100,0 \\
\hline $8^{a}$ & 100,0 & 100,0 & 100,0 & 100,0 & 100,0 & 88,9 & 100,0 & 100,0 \\
\hline $9^{a}$ & 100,0 & 81,8 & 100,0 & 100,0 & 100,0 & 33,3 & 100,0 & 100,0 \\
\hline $10^{\mathrm{a}}$ & 100,0 & 89,0 & 100,0 & 100,0 & 100,0 & 40,0 & 100,0 & 77,8 \\
\hline $\mathrm{R}$ & Repetições & & SMC & Aus & latéri & nica & & \\
\hline $4^{\circ} \mathrm{C}$ & Temperatura d & ius $\mathrm{Ce}$ & $\mathrm{CM}$ & Prese & natéria & nica & & \\
\hline
\end{tabular}




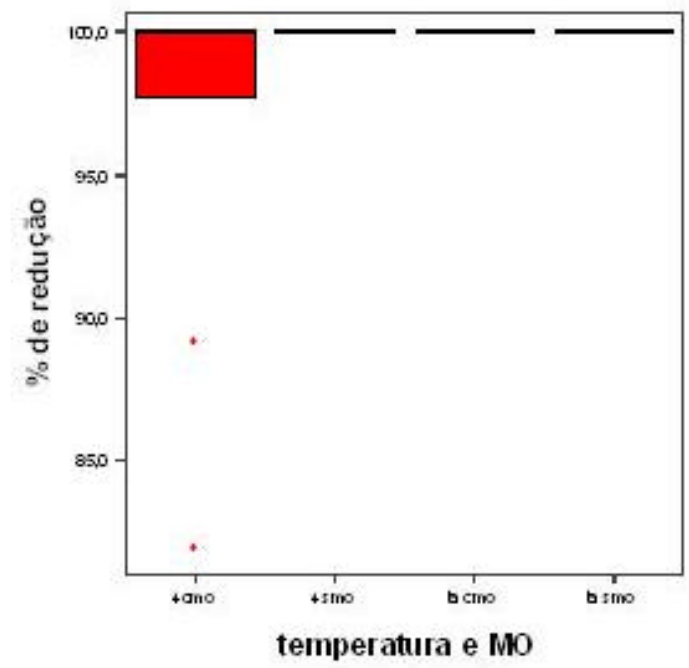

Ta Temperatura ambiente $\left(21 \pm 2^{\circ} \mathrm{C}\right)$ SMO Ausência de matéria orgânica

$4{ }^{\circ} \mathrm{C}$ Temperatura de 4 Graus Celsius CMO Presença de matéria orgânica

Fig. 1-Atividade micobactericida do hipoclorito de sódio 2,5\% em placas com meio de Middlebrook 7H11, em diferentes condições de temperatura e na presença ou ausência de matéria orgânica.

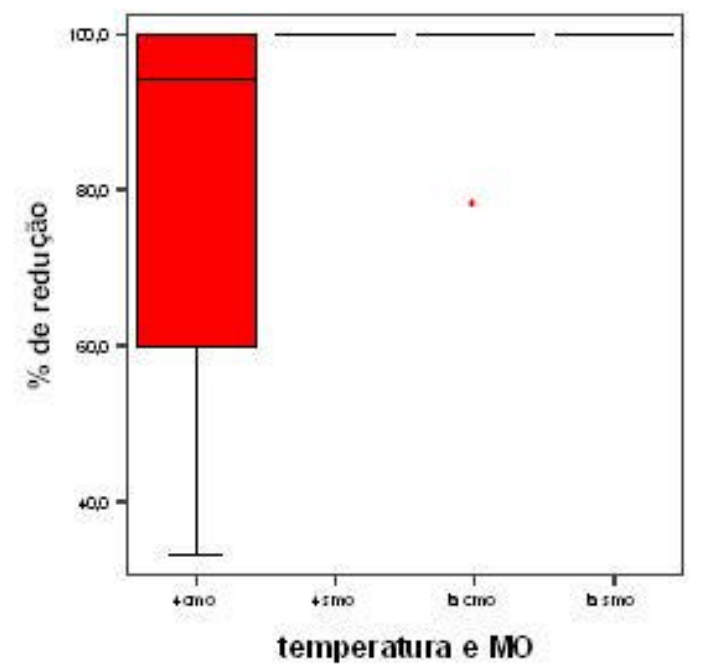

$\begin{array}{llll}\text { Ta } & \text { Temperatura ambiente }\left(21 \pm 2^{\circ} \mathrm{C}\right) & \text { SMO } & \text { Ausência de matéria orgânica } \\ 4^{\circ} \mathrm{C} & \text { Temperatura de } 4 \text { Graus Celsius } & \text { CMO } & \text { Presença de matéria orgânica }\end{array}$

Fig. 2 - Atividade micobactericida do hipoclorito de sódio 2,5\% em tubos com meio de Stonebrink, em diferentes condições de temperatura e na ausência ou presença matéria orgânica.

A utilização de microscopia óptica na leitura das placas favorece uma contagem precisa em menor período de tempo e é um aspecto que valoriza o teste realizado em placas (MARCONDES, 2002; MARCONDES et al., 2006; Dів et al., 2006). A visualização tardia de colônias em meios de cultura tradicionais é um fator que limita a recomendação dos testes que avaliam a atividade micobactericida de desinfetantes químicos
(Pinheiro et al., 1992, Pinheiro et al., 1997; Pinheiro, 2001).

A observação microscópica efetuada nas placas detectou o início do crescimento das U.F.C. aos 3 dias pós semeadura (p.s), resultando na recomendação de leitura aos 7 dias p.s. onde se pode quantificar e observar ocrescimento de colônias com aspecto rugoso, bordos irregulares e de coloração acastanhada 
(Fig. 3). Nos tubos, a visualização das U.F.C. sem ajuda de microscópio iniciou-se a partir do $21^{\circ}$ dia p.s. sendo a leitura feita somente no $28^{\circ}$ dia (Fig. 4). A visualização microscópica do crescimento de colônias (M. bovis), com aspecto semelhante, obtido no meio decultura de Middlebrook7H11 a partir do quinto dia pós-semeadura (Fig. 3), também foi observado por MARCONDEs et al. (2006) que, trabalhando com a estirpe padrão $M$. bovis AN5, constataram que as colônias podiam ser melhor visualizadas a partir do $5^{\circ} \mathrm{e} 6^{\circ}$ dia pós semeadura. A leitura efetuada em tubos aos 28 dias p.s. é recomendada em trabalhos que avaliam a atividade micobactericida de desinfetantes químicos (PInHeIro, 1990). A precocidade de tempo de leitura bem como contagem mais precisa é o que diferencia a técnica da camada delgada frente as demais técnicas tradicionalmente utilizadas.

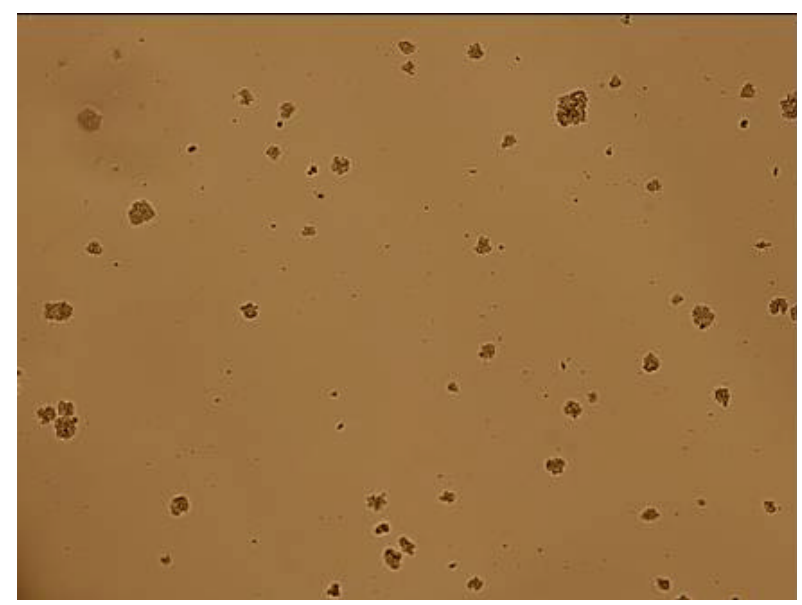

Fig. 3 - Colônias de M. bovis em placa com meio de Middlebrook 7H11, com 7 dias de cultivo. Microscopia ótica sob aumento de $100 \mathrm{x}$.

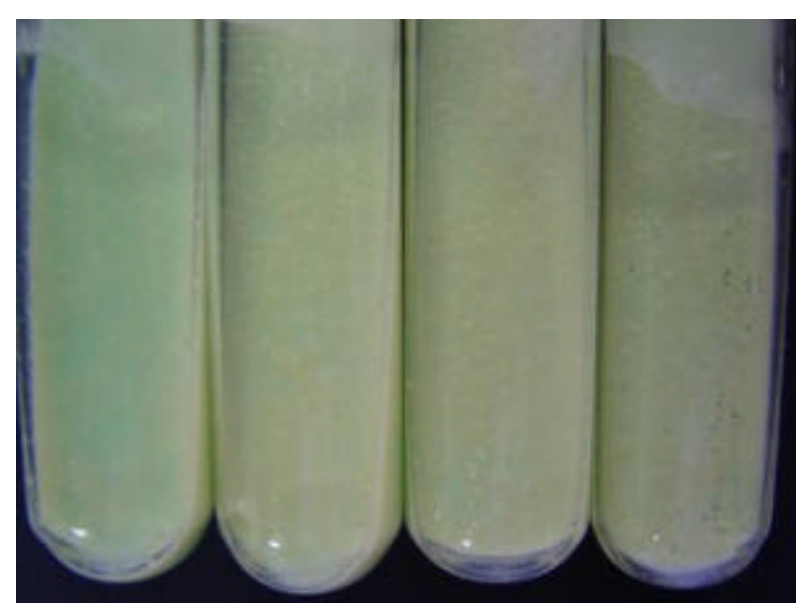

Fig. 4 - Colônias de M. bovis em tubos de meio de Stonebrink com 21 dias de Cultivo.
O resultado das contagens de U.F.C. obtido nas duas técnicas foi semelhante ( $p>0,05$, teste de MannWihtney) e indicou que à temperatura ambiente, na ausência e presença de matéria orgânica, o hipoclorito de sódio apresentou uma atividade micobactericida de $100 \%$ (Fig. 1). A boa atividade micobactericida dos clorados já foi descrita anteriormente (COSTIGAN, 1936; Smith, 1971; Pinheiro, 1990; CAstilloGuerrero, 1991). À temperatura de $4^{\circ} \mathrm{C}$, na ausência de matéria orgânica, o produto manteve a atividade micobactericida a 100\%, já quando submetido à presença de matéria orgânica sua atividade foi reduzida (teste de KruskalWallis e teste de Dunn; $\mathrm{p}<0,05)$. O percentual de redução foi maior quando na ausência de matéria orgânica e à temperatura ambiente (teste de MannWihtney; $\mathrm{p}<0,05)$. A diminuição da atividade micobactericida do hipoclorito de sódio na presença de matéria orgânica já foi relatada por HeKMATI; Bradley, (1979), Gélinas; Goulet (1983) e Pinheiro (1990).

Dentre os fatores que podem influenciar a atuação dos hipocloritos são mencionados o $\mathrm{pH}$, a temperatura, a concentração do produto e a matéria orgânica (HeKmatr;BRadley, 1979; G Élinas;Goulet, 1983; R ubin, 1983; World Health Organization, 1984). O efeito da temperatura sobre os produtos clorados foi demonstrado por CostigAn (1936) e DychDALA(1983), os quais constataram que o aumento da temperatura ocasionou um aumento da atividade bactericida do desinfetante.

\section{CONCLUSÃO}

A técnica de cultivo de micobactérias em camada delgada no meio de Middlebrook 7H11 se mostrou viável para realização de testes de desinfetantes quandocomparada ao testerealizadoem meio deStonebrink (28 dias) e permitiu uma visualização precoce das micobactérias (média de 7 0dias). A atividade micobactericida do hipoclorito de sódio só foi prejudicada quando houve associação da presença de matéria orgânica e temperatura de $4^{\circ} \mathrm{C}$.

\section{REFERÊNCIAS}

ACHA, P.N.; SZYFRES, B. Zoonosis y enfermedades transmisibles comunes al hombre y a los animales. 2. ed. Washington: Organización. Panamericana de la Salud, 1986. p.174-185. (Publicacíon científica, 503).

CASTILLO GUERRERO, A. Determinação da concentração ótima do hipoclorito de sódio para destruir Mycobacterium fortuitum em presença de quantidades variáveis de fezes de bovino como fonte de matéria orgânica. 1991. 47 f. Dissertação (Mestrado em Epidemiologia Experimental e 
Aplicada às Zoonoses) - Faculdade de Medicina Veterinária e Zooctecnia da Universidade de São Paulo, São Paulo, 1991.

CASTILLO GUERRERO, A.; PINHEIRO, S.R.; MORAIS, Z.M.; VASCONCELLOS, S.A.; ITO, F.H.; FERREIRA NETO, J.S. influência da matéria orgânica na atividade micobactericida do hipoclorito de sódio comercial com 2,5\% de cloro ativo. Brazilian Journal of Veterinary Research and Animal Science, v.30, p.211-216, 1993. Suplemento.

CENTRO PANAMERICANO DE ZOONOSIS. Bacteriologia de la tuberculosis humana y animal. Buenos Aires: Organización Panamericana de la Salud, 1979. v.11. 63p. (Serie de Monografias Científicas y Técnicas, 1982).

COSTIGAN, S.M. Effectiveness of hot hypochlorite of low alkalinity in destroying $M$. tuberculosis. Journal of Bacteriology, v.3, 1936.

DIB, C.C.; MORAIS, Z.M.; SOUZA, G.O.; AMAKU, M.; BENITES, N.R.; PINHEIRO, S.R. Utilização de uma técnica rápida para o diagnóstico de Mycobacterium bovis em amostras de leite experimentalmente inoculadas. Arquivos do Instituto Biológico, São Paulo, v.73, n.2, p.149-155, 2006.

DURMAZ, R.; DURMAZ, B.; GUREL, M. Mycobacterium tuberculosis culture in Middlebrook 7H11 agar versus Löwenstein-Jensen medium. Turkiye Mikrobiyoloji Bulteni, v.19, n.2, p.88-94, 1985.

DYCHDALA, G.R. Chlorine and chlorine compounds. In: BLOCK, S.S. (Ed.). Disinfection, sterilization and preservation. 3.ed. Philafelphia: Lea \& Febiger, 1983. p.157-182.

GÉLINAS, P.; GOULET, J. Neutralization of the activity of eight disinfectants by organic matter. Journal of Applied Bacteriology, v.54, p.243-247, 1983.

HEKMATI, M.; BRADLEY, R.L. Effect of milk constituents on the persistence of sodium hypochlorite sanitizer. Journal of Dairy Science, v.62, p.47-48, 1979.

IDIGORAS. P.; PÉREZ-TRALLERO, E.; ALCORTA, M.; GUTIÉRREZ, C.; MUÑOZ-BAROJA, I. Rapid detection of tuberculous and non-tuberculous Mycobacteria by microscopic observation of growth on Middlebrook 7H11 agar. European Journal of Clinical Microbiology Infectious Diseases, v.14, n.1, p.6-10, 1995.

KLEEBERG, H.H. Tuberculosis humana de origen bovino y salud pública. Revue Cientifique et Technique Office International des Epizzoties, v.3, p.55-76, 1984.

MARCONDES, A. G. Padronização da técnica de cultivo em camada delgada de agar Middlebrook 7 H11 para isolamento de Mycobacterium bovis. 2002. 115f. Dissertação (Mestrado em Epidemiologia Experimental e Aplicada às Zoonoses) -
Faculdade de Medicina Veterinária e Zootecnia da Universidade de São Paulo, São Paulo, 2002.

MARCONDES, A.G.; SHIKAMA, M. L.; VASCONCELLOS, S. A.; BENITES, N. R., MORAIS, Z. M.; ROXO, E.; DIAS, R. A.; LEÃO, S. L.; PINHEIRO, S. R. Comparação entre a técnica de cultivo em camada delgada de agar Middlebrook 7H11 e meio de Stonebrink para isolamento de Mycobacterium bovis em amostras de campo. Brazilian Journal of Veterinary Research and Animal Science, v.43, n.3, p.362-369, 2006.

MEJIA, G.I.; CASTRILLON, L.; TRUJILLO, H.; ROBLEDO, J.Á. Microcolony detection in 7H11 thin layer culture is an alternative for rapid diagnosis of Mycobacterium tuberculosis infection. International Journal of Tuberculosis and Lung Disease, v.3, n.2, p.138142, 1999.

PINHEIRO, S.R. Avaliação da atividade micobactericida de desinfetantes químicos sobre estirpes de Mycobacterium avium, isoladas de suínos abatidos no estado de Santa Catarina, no ano de 1999. 2001. f. 14-33. Tese (livre Docência) Faculdade de Medicina Veterinária e Zootecnia da Universidade de São Paulo, São Paulo, 2001.

PINHEIRO, S.R.; VASCONCELLOS, S.A.; MORAIS, Z. M.; FERREIRA NETO, J.S.; SINHORINI, I.L.; ITO, F.H.; CÔRTES, J.A. Padronização de teste "in vitro" para a avaliação da atividade micobactericida do hipoclorito de sódio e de uma combinação de aldeídos. Influência da passagem da estirpe teste (Mycobacterium bovis AN5) em hamsters. Arquivos do Instituto Biológico, São Paulo, v.64, n.1, p.11-22, 1997.

PINHEIRO, S.R.; VASCONCELLOS, S.A.; ITO, F.H.; FERREIRA NETO, J.S.; MORAIS, Z.M. Influência da matéria orgânica na atividade micobactericida de cinco desinfetantes de uso pecuário. Brazilian Journal of Veterinary Research and Animal Science, v.29, n.1, p.51-60, 1992.

PINHEIRO, S.R. Influência da matéria orgânica na atividade micobactericida de cinco desinfetantes químicos de uso pecuário. 1990. 47p. Dissertação (Mestrado em Epidemiologia Experimental e Aplicada às Zoonoses) Faculdade de Medicina Veterinária e Zootecnia, Universidade de São Paulo, São Paulo, 1990.

POLIAKOV, A.A. Veterinarnaya desinfektsia. 4.ed. Moscú: Kolos, 1975. 278p.

RUBIN, J. Agents for disinfection and control of tuberculosis. In: BLOCK, S.S. (Ed.). Disinfection, sterilization and preservation. 3.ed. Philadelphia: Lea \& Febiger, 1983. p.414-421.

SCHABERG, T.; REICHERT, B.; SCHULIN, T.; LODE, H.; MAUCH, H. Rapid drug susceptibility testing of Mycobacterium tuberculosis using conventional solid media. Berlin, Germany. Europe Respiratory Journal, v.8, n.10, p.1688-1693, 1995. 
SMITH, C.R. Mycobactericidal agents. In: BLOCK, S.S. (Ed.). Disinfection, sterilization and preservation. Philadelphia: Lea \& Febiger, 1971. p.504-513.

UNIVERSIDAD DE LAS NACIONES UNIDAS. Programa de biotecnologia para Latinoamérica y el Caribe BIOLAC. Red Latinoamaricana y del Caribe de tuberculosis - RELACTB. Curso: Nuevas tecnologias para el diagnóstico y pruebas de susceptibilidad a drogas de $M$. tuberculosis para paises en vias de desarollo. La Paz, Bolivia, 1998. p.18-21.

VERA, A.; VOLKOVSKY, G.; SANCHEZ, I.; COTRINA, N. Acción desinfectantes contra M. bovis: hidróxido de sódio,mezcla de este producto con formaldehido, productos clorados y acido peracético. Ciencia e Tecnologia Agrícola eVeterinária, v.7, p.29-38, 1985.
WANG, G.Q.; ZHANG, C.W.; LIU, H.C.; CHEN, Z.B. Comparison of susceptibilities of M. tuberculosis H37Ra and $M$. chelonei subsp. Abcessus to disinfectants. Biomedical and environmental sciences, v.18, p.124-127, 2005.

WELCH, D.F.; GURUSWAMY, A.P.; SIDES, S.J.; SHAW, C.H.; GILCHRIST, M.J. Timely culture for mycobacteria which utilizes a microcolony method. Journal of Clinical Microbiology, v.31, n.8, p.2178-2184, 1993.

WORLD HEALTH ORGANIZATION. Guidelines on disinfection in animal husbandry for prevention and control of zoonotic diseases. Geneva: WHO, 1984. 49p. (WHO/ $\mathrm{VPH} / 84.4)$.

Recebido em 29/9/07

Aceito em 6/12/08 